\title{
IMPACTOS DA NECESSIDADE DE ISOLAMENTO SOCIAL EM IDOSOS NA PANDEMIA DE COVID-19: UMA REVISÃO INTEGRATIVA
}

Camila Kuhn Vieira; (Bolsista de Mestrado CAPES). Universidade de Cruz Alta - UNICRUZ/RS. E-mail: camilakuhn1994@hotmail.com

Adriana da Silva Silveira; Universidade de Cruz Alta - UNICRUZ/RS. E-mail: adri01rp@gmail.com Carine Nascimento da Silva; (Bolsista de Mestrado CAPES). Universidade de Cruz Alta - UNICRUZ/RS. E-mail: kaca_nascimento@hotmail.com Solange Beatriz Billig Garces; Universidade de Cruz Alta - UNICRUZ/RS. E-mail: sgarces@unicruz.edu.br Patrícia Dall'Agnol Bianchi; Universidade de Cruz Alta - UNICRUZ/RS. E-mail: pbianchi@unicruz.edu.br Dinara Hansen Costa; Universidade de Cruz Alta - UNICRUZ/RS. E-mail: dhansen@unicruz.edu.br Cristina Thum; Universidade de Cruz Alta - UNICRUZ/RS. E-mail: cristinathum@unicruz.edu.br Carolina Böettge Rosa; Pontifícia Universidade Católica do Rio Grande do Sul - PUCRS. E-mail: carolboettge@gmail.com

\section{RESUMO}

A COVID-19 é uma doença infecciosa que surgiu em Wuhan, na China e se alastrou, virando uma pandemia. Para evitar a disseminação do vírus e achatar a curva epidêmica vários países adotaram medidas de isolamento social, porém, essas medidas trazem impactos na rotina e na saúde mental dos idosos. Objetivo: Investigar os impactos do isolamento social para a população idosa devido a Pandemia do novo - COVID-19. Métodos: Revisão integrativa, realizada BVS e Pubmed por meio dos descritores "Social isolation" AND "Elderly" AND "Covid-19". Os critérios de inclusão: textos (artigos) completos grátis, publicados no período de 2019 a 2020, em português, inglês e espanhol e que abordem os impactos do isolamento social em idosos na pandemia do Covid-19. E, como critérios de exclusão: textos incompletos, livros, capítulos de livros, artigos publicados anteriores do período de 2019 e outros idiomas. Resultados: Foram encontrados 243 artigos, sendo 40 pré-selecionados, 8 duplicados e 11 selecionados. Destacam-se entre os estudos analisados os impactos no comportamento nutricional (Ganho de peso), mudança no estado civil, ansiedade, depressão, desmotivação, estresse, síndrome do pânico, insônia, preocupação financeira, podendo culminar no suicídio, e ainda, agravos de patologias pré-existentes assim como outros sintomas de sofrimento psíquico. Conclusão: É possível compreender que o isolamento social, apesar de necessário neste período de pandemia do COVID-19, traz efeitos prejudiciais à saúde física e mental de idosos que podem perdurar após esse período ainda indeterminado. Logo, as políticas de enfrentamento do Covid-19 devem se atentar na restauração da funcionalidade e do bem-estar dos idosos.

Palavras-chave: Isolamento Social; Idoso; Pandemia.

Agradecimentos: A Coordenação de Aperfeiçoamento de Pessoal de Nível Superior - CAPES, ao Grupo Interdisciplinar de Estudos do Envelhecimento Humano (GIEEH) e ao Programa de Pós-Graduação em Práticas Socioculturais e Desenvolvimento Social da Universidade de Cruz Alta - UNICRUZ/RS. 